\title{
Equivalent outcomes with small right anterior thoracotomy and sternotomy for mitral valve repair
}

\author{
Michael Bowdish ${ }^{1}$, Ramsey Elsayed ${ }^{1}$, James Tatus ${ }^{1}$, Robbin Cohen $^{1}$, Wendy Mack ${ }^{1}$, \\ Brittany Abt ${ }^{1}$, Mark Barr ${ }^{1}$, and Vaughn Starnes ${ }^{2}$ \\ ${ }^{1}$ University of Southern California \\ ${ }^{2}$ Keck School of Medicine, University of Southern California
}

June 4, 2020

\begin{abstract}
Background: Controversy exists regarding durability and survival after mitral valve repair between sternotomy and a small right anterior thoracotomy approaches. Methods: Between February 2004 and July 2015, 410 patients underwent mitral valve repair via either sternotomy $(\mathrm{ST}, \mathrm{n}=135)$ or small right anterior thoracotomy (RAT, $\mathrm{n}=275$ ). Mean follow up was 72.7 ? 38.9 months. Postoperative echocardiograms were obtained in 310 patients (75.6\%) at a mean of 20.3 ? 21.4 months. Results: Overall survival at 1, 3, 5, and 10 years were 96.3, 93.0, 93.0, and 91.4\% for the ST group and 99.3, 98.9, 98.4, and 97.0\% for the RAT group (Log-Rank p = 0.004). There was no difference between groups in the cumulative incidence of need for mitral valve reoperation or progression of mitral regurgitation $(\mathrm{MR})$ considering death as a competing outcome over time ( $\mathrm{p}=0.94$ and 0.53 , respectively). Propensity score weighted multivariate Cox Proportional hazard modeling built on baseline differences between the RAT and ST groups, showed presence or absence of posterior or anterior leaflet pathology was not associated with mortality, need for reoperation, or progression of MR. A RAT approach was associated with a decreased mortality on adjusted analysis (hazard ratio, $0.32,95 \%$ confidence interval, $0.13-0.82, \mathrm{p}=0.018$ ), however, this result was less significant when those with coronary artery disease were removed (hazard ratio, 0.34, 95\% confidence interval, 0.12-0.96, $\mathrm{p}=0.041$ ). Conclusions: Mitral valve repair via a small right anterior thoracotomy incision in select patients can be performed with surgical results and survival that are equivalent to the sternotomy approach.
\end{abstract}

\section{Introduction}

While mitral valve repair is widely accepted to be superior to replacement in appropriate cases, the optimal surgical approach to the mitral valve (MV) continues to evolve[1]. The traditional approach to the MV is via a full sternotomy. This approach provides excellent exposure to the heart, great vessels, and MV, allows for central arterial and venous cannulation, and allows the ability to perform concomitant cardiac procedures as well as optimally and expeditiously deal with complications[1].

The "minimally invasive techniques" include a variety of approaches to the MV via smaller incisions. The most common minimally invasive approaches to the MV are a small right anterior thoracotomy and a lower hemisternotomy. Reported advantages of less invasive approaches include less blood loss with fewer transfusions, decreased ventilation times, reduced intensive care and overall hospital lengths of stay, and a reduced time to return to normal activity[2]. Despite these advantages, the less invasive approaches are technically more challenging, require specialized training and equipment, and in some cases, are associated with higher rates of stroke, aortic dissection, and groin complications associated with peripheral cannulation [3].

While many studies have shown equivalent perioperative outcomes of less invasive MVr to standard sternotomies, the number of studies examining long term mortality and valve durability are somewhat limited[4- 
12]. In the present study, we sought to perform a comparative longitudinal analysis of risk factors for death, reoperation, and progression of mitral regurgitation after $\mathrm{MVr}$ performed via a full sternotomy and our preferred minimally invasive approach to the MV, a small right anterior thoracotomy.

\section{Materials and Methods}

Patient selection, data collection, endpoints

This study was conducted in accordance with the "Guidelines for reporting mortality and morbidity after cardiac valve interventions" [13]. Overall methods and study design for this cohort of patients have been previously reported[14]. Briefly, this was a retrospective cohort study of consecutive patients undergoing $\mathrm{MVr}$ at a single institution between February 2004 and July 2015. The follow-up period closed July 2016. Prior to 2004, minimally invasive mitral repair was not routinely done and therefore these cases were excluded. MVr was defined as MV reconstruction with or without an annuloplasty ring. Patients who underwent MV annuloplasty alone (without valve reconstruction), were excluded. Patients undergoing concomitant cardiac procedures were included. The institutional review board of the University of Southern California Health Sciences Campus approved this study (HS-15-00509) and waived the requirement for patient consent. The senior author performed over $85 \%$ of the total procedures, and nearly $100 \%$ of the minimally invasive procedures.

Patients were divided into two groups based on the operative approach to MVr (Group 1 - MVr via small right anterior thoracotomy, RAT; Group $2-\mathrm{MVr}$ via full sternotomy, ST). Baseline characteristics and perioperative outcomes were identified through our institutional database. The primary endpoints were mortality, need for MV reoperation, and the progression of mitral regurgitation (MR). Follow up TTEs were obtained at the discretion of the physician. MR was coded 0 to 4 based on echocardiogram reports $(0=$ none, $1=$ trace, $2=$ mild, $2.5=$ mild-to-moderate, $3=$ moderate, $3.5=$ moderate-to-severe, $4=$ severe). Progression of MR was defined as worsening of MR by more than 2 grades.

\section{Operative technique}

Surgical approach was at the discretion of the operating surgeon. Routine chest computed tomography was not obtained. Cardioplegia was with high potassium 4:1 blood: crystalloid cardioplegia until July 2014, after which time, cold Del Nido cardioplegia was used. Moderate hypothermia $\left(32^{\circ} \mathrm{C}\right)$ was used in all cases.

In the ST group, conventional median sternotomy, ascending aorta and bicaval cannulation, and antegrade cardioplegia catheters were used (coronary sinus catheters are no longer placed routinely). In the RAT group, a small right anterior thoracotomy was made in the fifth intercostal space. Double lumen endotracheal intubation routine. Peripheral cannulation was preferentially utilized. Pericardial retraction sutures were placed and secured on protective red rubber "bumpers" on the chest wall. A left ventricular vent was inserted through the right superior pulmonary vein and tunneled through the chest wall. After MVr, two 32 -French chest drains were placed in the mediastinal and pericardial spaces for postoperative drainage. The intercostal space was approximated with heavy suture. Use of subpleural pain catheters was at the discretion of the surgeon.

MV exposure and the approach to MVr was similar in both groups. The MV was typically accessed via the interatrial sulcus, although transseptal and left atrial dome approaches were also utilized. Posterior leaflet MVr generally involved resection of the diseased segment, annular plication and reconstruction of the posterior leaflet. The anterior leaflet was repaired by the placement of Gore-Tex neochordae (W.L. Gore \& Associates, Inc., Flagstaff, AZ, USA) or resection and reconstruction. A true-sized, partial posterior MV annuloplasty was primarily utilized.

\section{Statistical Analysis}

Statistical analyses were performed using SAS version 9.4 (SAS Institute, Inc., Cary, NC., USA). For the two surgical approaches, baseline and postoperative outcomes were analyzed using frequency tables and histograms. Continuous variables are reported as mean and standard deviation if normally distributed, or 
as median and interquartile range if not normally distributed. Continuous variables were compared between the two groups using either two sample independent t-tests or the Wilcoxon rank sum test, depending on normality. Categorical variables were compared using the Chi square or Fischer's exact test, depending on expected values.

Unadjusted survival between groups was compared by Kaplan-Meier methods and comparisons made between groups by the Log-Rank test. Death was accounted for in models of cumulative incidence of mitral reoperation and progression of MR as described in the Fine-Grey Model $[15,16]$.

Multivariable logistic regression was performed to determine which preoperative variables were associated with a minimally invasive surgical approach. A minimally invasive surgical approach was modeled as the dependent variable and the following independent variables were included in the model based on the univariate analysis, the medical literature, and biologic plausibility: age, race (white vs. non-white), previous cardiac surgery (yes vs. no), need for concurrent cardiac procedure (yes vs. no), location of MV leaflet involvement on preoperative echo (anterior vs. posterior vs. bileaflet), MV lesion etiology (degenerative vs. non-degenerative), and diabetes (yes vs. no). The C-statistic and Hosmer and Lemeshow goodness-of-fit test were reported for the model.

To estimate the impact of surgical approach on the outcomes of interest, the multivariable logistic regression model was used to calculate a subject's propensity for having a minimally invasive surgical approach. Propensity scores were then entered in to a separate Cox proportional hazard regression model to calculate adjusted hazard ratios for each outcome. Statistics with a p value less than 0.05 were considered statistically significant.

\section{Results}

\section{Preoperative and operative characteristics}

A total of 410 patients underwent MVr during the study period. A small right anterior thoracotomy was performed in 275 patients (RAT group), while 135 had a standard median sternotomy (ST group).

Preoperative characteristics are shown in Table 1 . There were no differences between groups in gender, race, body mass index, New York Heart Association classification, preexisting atrial fibrillation, congestive heart failure, hyperlipidemia, hypertension, chronic obstructive pulmonary disease, renal disease, or previous stroke or myocardial infarction. RAT patients were significantly younger, had slightly higher ejection fractions, were less likely to have had previous cardiac surgery, and more likely to have posterior MV leaflet involvement, severe mitral regurgitation, and a degenerative etiology of MV disease.

Operative data is presented in Table 2. Significant differences were seen between groups for multiple variables. As compared to the ST group, the RAT group had shorter cross clamp and cardiopulmonary bypass times, however, the ST group was significantly more likely to have a concomitant cardiac surgery procedure at the time of MVr. There were also differences in locations of MVrs, with more posterior repairs in the RAT group and more anterior repairs the ST group. There was one conversion to full sternotomy in the RAT group.

\section{Unadjusted Analysis of Mortality, Need for Mitral Reoperation, and Progression of Mitral Regurgitation}

Mean follow up for mortality was $72.7 \pm 38.9$ months and was complete in all 410 patients. Thirty-day mortality was $1.5 \%$ in the ST group and $0.4 \%$ in the RAT group and was not statistically significantly different between groups (Odds Ratio (OR) 0.24, 95\% CI 0.02-2.7, $\mathrm{p}=0.25$ ). Overall, incidence of death was $7.4 \%$ in the ST group and $1.8 \%$ in the RAT group (OR 0.23, 95\% CI 0.08-0.69, $\mathrm{p}=0.009$ ). Kaplan-Meier estimates of survival at 1,3,5, and 10 years were $96.3,93.0,93.0$, and $91.4 \%$ for the ST group and 99.3, 98.9, 98.4, and 97.0\% for the RAT group (Log-Rank $\mathrm{p}=0.004$, Figure 1 and Supplemental Table 1 ).

Mean follow up for need for MV reoperation was $59.7 \pm 39.0$ months and was complete in $313(76.3 \%)$ patients. Overall incidence of need for reoperation was $6.1 \%$ in the RAT group and $7.1 \%$ in the ST group (OR $0.85,95 \%$ CI $0.33-2.20, \mathrm{p}=0.74$ ). The cumulative incidence of need for MV reoperation with death as 
a competing outcome at 1,3 , and 5 years were $5.8,9.7$, and $9.7 \%$ for the ST group and $2.3,6.3$, and $11.7 \%$ for the RAT group (Grey's Test for Equality of Cumulative Incidence Functions, $\mathrm{p}=0.94$, Figure 2 and Supplemental Table 1 ).

Mean follow up for progression of mitral regurgitation two or more grades was $20.3 \pm 21.4$ months and was complete in $310(75.6 \%)$ of patients. Overall incidence of progression of MR was $8.5 \%$ in the RAT group and $10.3 \%$ in the ST group (OR $0.80,95 \%$ CI $0.36-1.81, \mathrm{p}=0.67$ ). The cumulative incidence of progression of MR with death as a competing outcome at 1,3, and 5 years were 5.6, 12.1, and $36.7 \%$ for the ST group and 3.6, 9.7, and $22.5 \%$ for the RAT group (Grey's Test for Equality of Cumulative Incidence Functions, $\mathrm{p}=0.53$, Figure 3 andSupplemental Table 1 ).

Propensity Analysis and Adjusted Outcomes

Given the significant differences in baseline characteristics between the RAT and ST groups, seven baseline variables were used to create a logistic regression model for selection to a RAT or ST approach.Figure 4 shows the results of the logistic regression model predicating selection to a RAT or ST approach. Those more likely to undergo a sternotomy were older, of non-white race, more likely to have had a previous cardiac operation, and to be having a concomitant procedure, while those undergoing a small right anterior thoracotomy were more likely to have posterior leaflet pathology, degenerative MV disease, and to have diabetes. The area under the receiver operating curve (c-statistic) for the model was 0.84 and Homer and Lemeshow Goodness-of-fit test was not statistically significant $(\mathrm{p}=0.25)$, demonstrating good model discrimination and limited collinearity and interactions (Supplemental Figure 1 ).

Adjusted multivariable Cox-Proportional hazard outcomes are shown inFigure $\mathbf{5}$. The presence of any anterior or posterior repair was not predictive of mortality, however, a small right anterior thoracotomy approach was associated with decreased mortality (Hazard Ratio (HR) 0.32, 95\% CI 0.13-0.82, p=0.018). Neither the need for MV reoperation or progression of mitral regurgitation were affected by the type of repair or operative approach.

\section{Sensitivity Analysis}

To examine the possibility that these results were confounded by either a concurrent or previously coronary artery bypass grafting procedure, a separate analysis was conducted without these 25 patients. In this analysis, there was a less significant survival benefit on unadjusted Kaplan-Meier estimates of survival between surgical approaches ( $\log -$ Rank $\mathrm{p}=0.05)$, however, a survival benefit was seen for the small right anterior thoracotomy approach on propensity adjusted multivariable Cox-Proportional hazard modeling (HR 0.341, 95\% CI 0.12-0.96, $\mathrm{p}=0.04$ ). Results similar to the primarily analyses were seen with the need for mitral reoperation and progression of MR outcomes (data not shown). No effect was seen in any adjusted analysis based on location of MVr (data not shown).

\section{Conclusions}

MV surgery, including MVr, has continued to evolve over the past several decades[1,17]. MVr is widely accepted as both preferable and superior to replacement when the repair is expected to feasible, durable, and associated with a low morbidity and mortality[18]. In our recently published series of 446 patients undergoing MVr, survival was excellent at $97 \%, 96 \%, 95 \%$, and $94 \%$ at 1,3, 5 , and 10 years, and the cumulative incidence of progression of mitral regurgitation (MR) with mortality as a competing risk was $4.7 \%, 10.5 \%, 21.1 \%$, and $35.8 \%$ at $1,3,5$, and 10 years[14]. Other contemporary studies have also demonstrated excellent survival and low rates of MR recurrence, suggesting that in the era of evolving technologies, the excellent results obtained with surgical MVr should not be forgotten[19-21].

The optimal approach to the MV remains debatable. Minimally invasive approaches to the MV were developed, and continue to be developed and improved, with the hope of decreasing the morbidity and mortality associated with a standard sternotomy approach. While there are strong proponents of the minimally invasive approach, demonstrating a clear benefit over standard sternotomy has been difficult. Results of comparative 
studies are often contradictory, however, several studies suggest a minimally invasive approach can be associated with less blood product use, equivalent or shorter lengths of stay, decreased hospital readmissions, and equivalent perioperative morbidity and mortality [5-7,9-12]. The long-term benefits of minimally invasive MV approach when compared to a sternotomy approach are even less clear with far fewer studies with a comparator group and long-term outcomes. This is made more difficult by the lack of randomized controlled trials, and given lack of surgeon equipoise, the unlikelihood that an appropriately designed trial will be conducted.

The present study used a propensity score model to compare long term survival, need of mitral reoperation, and progression of mitral regurgitation with two surgical approaches to MVr, the standard sternotomy, and our preferred minimally invasive approach, the small right anterior thoracotomy. The principle findings of our study were that overall survival was at least equivalent between groups, and there were no differences in the need for MV reoperation or progression of mitral regurgitation over time between groups.

Overall survival was excellent with both surgical approaches, and is comparable to other reports $[5,6,9,10,12]$. Perioperative mortality was $1.5 \%$ in the sternotomy group and $0.4 \%$ in the small right anterior thoracotomy group, and 10-year survival was $91.4 \%$ in the sternotomy group and $97.0 \%$ in the small right anterior thoracotomy group. After propensity adjustment on baseline factors predictive of operative approach, there was a protective benefit for the small right anterior thoracotomy approach, which was independent of the type of $\mathrm{MVr}$ (HR 0.32, 95\% CI 0.13-0.82, $\mathrm{p}=0.018$ ). This protective benefit, while statistically significant, should be viewed with caution and should not be interpreted to suggest that a right anterior thoracotomy approach is superior to a standard sternotomy approach.

One should carefully interpret these results within the context of this study. The higher mortality rates in the sternotomy group likely reflects their sicker nature and inclusion of those needing coronary revascularization, despite risk adjustment. This is seen in our sensitivity analysis with lessening of survival "benefit" with removal of coronary revascularization patients indicating, albeit a good logistic model, all bias was not removed. However, the analysis does strongly support equivalent long-term survival between these two operative approaches. Patient selection (body habitus, anatomy, etc) partially accounts for our excellent minimally invasive results, for which we offer no apologies.

Our rates of MV reoperation and progression of MR over time are somewhat difficult to interpret in the context of the literature as we appropriately included death as a competing outcome. That said, the important finding here is that after risk adjustment for differences in selection of operative approach, there does not seem to be any more or less need for MV reoperation or progression of MR in either group.

There are numerous limitations to this study, some of which are discussed above. This was a retrospective cohort study from a single center and has the inherent limitations of this type of analysis. Selection to a surgical approach was not randomized and was highly biased based on preoperative characteristics. While we have attempted to adjust for these baseline differences with our statistical modeling, inherently not all bias is removed.

In conclusion, $\mathrm{MVr}$ via a small right anterior thoracotomy incision in select patients can be performed with surgical results and survival that are equivalent to the sternotomy approach. Growing evidence supports the safety and durability of less invasive MVr, making it the preferred approach of many experienced MV surgeons.

\section{Figure Legends}

Figure 1. Kaplan-Meier analysis of survival after MVr, stratified by type of surgical approach with $95 \%$ confidence bands. Log-Rank comparison between strata $=0.004$.

Figure 2. Nonparametric estimates of cumulative incidence of the probability of reoperation with death as a competing outcome stratified by approach to MVr (sternotomy, ST, solid line; small right anterior thoracotomy, RAT, dashed line). Grey's test for equality of cumulative incidence functions between strata, $\mathrm{p}=0.94$. 
Figure 3. Nonparametric estimates of cumulative incidence of the probability of progression of mitral regurgitation more than 2 grades with death as a competing outcome stratified by approach to MVr (sternotomy, ST, solid line; small right anterior thoracotomy, RAT, dashed line). Grey's test for equality of cumulative incidence functions between strata, $\mathrm{p}=0.53$.

Figure 4. Forest plot of multivariable logistic regression model of operative approach. Odds ratio (OR) > 1.0 favors small right anterior thoracotomy approach (bars represent 95\% confidence intervals).

Figure 5. Forest plot of propensity adjusted multivariable analysis of mortality, mitral reoperation, and recurrence of MR.

Supplementary Figure 1. Receiver operator curve for multivariable logistic regression model of operative approach.

Table 1. Preoperative characteristics

\begin{tabular}{|c|c|c|c|}
\hline & $\begin{array}{l}\text { Small Right Anterior } \\
\text { Thoracotomy }(n=275)\end{array}$ & Sternotomy $(n=135)$ & p-value \\
\hline Preoperative & Preoperative & Preoperative & Preoperative \\
\hline Characteristics & Characteristics & Characteristics & Characteristics \\
\hline Age (years) & $59(50,67)$ & $67(58,76)$ & $<0.0001$ \\
\hline Male & $187(68.0)$ & $86(63.7)$ & 0.386 \\
\hline Non-white race & $56(20.4)$ & $38(28.2)$ & 0.078 \\
\hline $\begin{array}{l}\text { Body Mass Index } \\
\left(\mathrm{kg} / \mathrm{m}^{2}\right)\end{array}$ & $25(23,28)$ & $25(23,28)$ & 0.784 \\
\hline $\begin{array}{l}\text { New York Heart } \\
\text { Association Class }\end{array}$ & & & 0.947 \\
\hline I & $35(20.8)$ & $19(22.1)$ & \\
\hline II & $73(43.5)$ & $34(39.5)$ & \\
\hline III & $45(26.8)$ & $25(29.1)$ & \\
\hline IV & $15(8.9)$ & $8(9.3)$ & \\
\hline Diabetes & $30(11.7)$ & $6(4.8)$ & 0.029 \\
\hline Atrial fibrillation & $30(18.9)$ & $13(15.9)$ & 0.563 \\
\hline $\begin{array}{l}\text { History of Congestive } \\
\text { Heart Failure }\end{array}$ & $99(38.5)$ & $52(41.3)$ & 0.605 \\
\hline Hyperlipidemia & $73(39.7)$ & $27(31.8)$ & 0.212 \\
\hline Hypertension & $154(59.5)$ & $64(50.8)$ & 0.090 \\
\hline $\begin{array}{l}\text { Chronic Obstructive } \\
\text { Pulmonary Disease }\end{array}$ & $21(5.7)$ & $16(13.0)$ & 0.166 \\
\hline $\begin{array}{l}\text { Prior myocardial } \\
\text { infarction }\end{array}$ & $15(6.3)$ & $8(6.9)$ & 0.816 \\
\hline $\begin{array}{l}\text { Prior cerebrovascular } \\
\text { accident }\end{array}$ & $11(4.6)$ & $3(3.7)$ & 0.285 \\
\hline Renal Insufficiency & $11(4.3)$ & $3(2.4)$ & 0.366 \\
\hline $\begin{array}{l}\text { Renal failure requiring } \\
\text { renal replacement } \\
\text { therapy }\end{array}$ & $8(2.1)$ & $1(0.3)$ & 0.165 \\
\hline Ejection Fraction (\%) & $61(57,66)$ & $60(50,65)$ & 0.0004 \\
\hline $\begin{array}{l}\text { Previous cardiac } \\
\text { surgery }\end{array}$ & $4(1.5)$ & $15(11.1)$ & $<0.0001$ \\
\hline $\begin{array}{l}\text { Prior mitral valve } \\
\text { surgery }\end{array}$ & $2(0.7)$ & $5(3.7)$ & 0.029 \\
\hline CABG & $0(0)$ & $7(5.2)$ & 0.0001 \\
\hline
\end{tabular}




\begin{tabular}{|c|c|c|c|}
\hline & $\begin{array}{l}\text { Small Right Anterior } \\
\text { Thoracotomy }(n=275)\end{array}$ & Sternotomy $(n=135)$ & p-value \\
\hline Any valve & $4(1.5)$ & $9(6.7)$ & 0.048 \\
\hline Preoperative Mitral & Preoperative Mitral & Preoperative Mitral & Preoperative Mitral \\
\hline $\begin{array}{l}\text { Valve Assessment } \\
\text { (Echocardiogram) }\end{array}$ & $\begin{array}{l}\text { Valve Assessment } \\
\text { (Echocardiogram) }\end{array}$ & $\begin{array}{l}\text { Valve Assessment } \\
\text { (Echocardiogram) }\end{array}$ & $\begin{array}{l}\text { Valve Assessment } \\
\text { (Echocardiogram) }\end{array}$ \\
\hline \multicolumn{4}{|l|}{ Leaflet involvement } \\
\hline Anterior & $20(7.3)$ & $32(23.7)$ & $<0.0001$ \\
\hline Posterior & $215(78.8)$ & $92(68.2)$ & \\
\hline Anterior and Posterior & $38(13.0)$ & $11(8.1)$ & \\
\hline Preoperative MR grade & & & 0.0002 \\
\hline Mild & $2(0.7)$ & $5(3.8)$ & \\
\hline Moderate & $30(7.4)$ & $32(24.2)$ & \\
\hline Severe & $238(88.1)$ & $95(72.0)$ & \\
\hline $\begin{array}{l}\text { Etiology of mitral } \\
\text { valve disease }\end{array}$ & & & $<0.0001$ \\
\hline Degenerative & $259(94.2)$ & $104(77.0)$ & \\
\hline Other & $16(5.8)$ & $31(23.0)$ & \\
\hline
\end{tabular}

Table 2. Operative characteristics

\begin{tabular}{|c|c|c|c|}
\hline & $\begin{array}{l}\text { Small Right Anterior } \\
\text { Thoracotomy }(n=275)\end{array}$ & Sternotomy $(n=135)$ & p-value \\
\hline \multicolumn{4}{|l|}{ Operative } \\
\hline \multicolumn{4}{|l|}{ Characteristics } \\
\hline $\begin{array}{l}\text { Cardiopulmonary } \\
\text { bypass time (minutes) }\end{array}$ & $73(61,93.5)$ & $110(80,140)$ & $<0.0001$ \\
\hline $\begin{array}{l}\text { Cross-clamp time } \\
\text { (minutes) }\end{array}$ & $48(39,63)$ & $74(55,104)$ & $<0.0001$ \\
\hline Concurrent procedure & $44(16.0)$ & $80(59.3)$ & $<0.0001$ \\
\hline CABG & $1(0.4)$ & $18(13.3)$ & $<0.0001$ \\
\hline Aortic valve & $1(0.4)$ & $16(11.9)$ & $<0.0001$ \\
\hline Tricuspid valve & $11(4.0)$ & $17(12.6)$ & 0.0001 \\
\hline Aortic procedure & $0(0.0)$ & $12(8.9)$ & $<0.0001$ \\
\hline Ablation procedure & $18(6.8)$ & $30(22.7)$ & $<0.0001$ \\
\hline Septal myectomy & $1(0.4)$ & $6(4.4)$ & 0.003 \\
\hline $\begin{array}{l}\text { Atrial septal defect } \\
\text { repair }\end{array}$ & $18(6.6)$ & $5(3.7)$ & 0.240 \\
\hline $\begin{array}{l}\text { Ventricular septal } \\
\text { defect repair }\end{array}$ & $0(0.0)$ & $2(1.5)$ & $0.108 \mathrm{c}$ \\
\hline IABP & $1(0.4)$ & $7(5.2)$ & $0.002 \mathrm{c}$ \\
\hline $\begin{array}{l}\text { Ventricular assist } \\
\text { device placement }\end{array}$ & $0(0)$ & $1(0.8)$ & 0.148 \\
\hline $\begin{array}{l}\text { Peripheral arterial } \\
\text { cannulation }\end{array}$ & $259(94.2)$ & $10(7.4)$ & $<0.0001$ \\
\hline $\begin{array}{l}\text { Need for second } \\
\text { cardiopulmonary } \\
\text { bypass }\end{array}$ & $5(1.8)$ & $4(3.0)$ & 0.457 \\
\hline $\begin{array}{l}\text { Type of mitral } \\
\text { annuloplasty }\end{array}$ & & & 0.0004 \\
\hline
\end{tabular}




\begin{tabular}{|c|c|c|c|}
\hline & $\begin{array}{l}\text { Small Right Anterior } \\
\text { Thoracotomy }(n=275)\end{array}$ & Sternotomy $(n=135)$ & p-value \\
\hline None & $0(0)$ & $7(4.5)$ & \\
\hline Partial & $275(100)$ & $126(95.5)$ & \\
\hline Complete & $0(0)$ & $0(0)$ & \\
\hline $\begin{array}{l}\text { Size of mitral } \\
\text { annuloplasty }\end{array}$ & $32(30,34)$ & $30(28,32)$ & 0.0004 \\
\hline \multicolumn{4}{|l|}{$\begin{array}{l}\text { Type of mitral valve } \\
\text { repair }\end{array}$} \\
\hline $\begin{array}{l}\text { Any posterior leaflet } \\
\text { repair }\end{array}$ & $250(90.9)$ & $102(75.6)$ & $<0.0001$ \\
\hline $\begin{array}{l}\text { Any anterior leaflet } \\
\text { repair }\end{array}$ & $69(25.1)$ & $47(34.8)$ & 0.040 \\
\hline $\begin{array}{l}\text { Isolated posterior } \\
\text { leaflet repair }\end{array}$ & $206(74.9)$ & $88(65.2)$ & 0.0001 \\
\hline $\begin{array}{l}\text { Isolated anterior leaflet } \\
\text { repair }\end{array}$ & $25(9.1)$ & $33(24.4)$ & \\
\hline Bileaflet repair & $44(16.0)$ & $14(10.4)$ & \\
\hline
\end{tabular}

\section{Table Legends}

Table 1. Preoperative characteristics

Table 2. Operative characteristics

Supplemental Table 1. Confidence intervals for time dependent figures

\section{Author Contributions:}

Concept/design: MB, RE, JT, RC, WM, MB, VS

Data collection: RE, JT, BA

Data analysis/interpretation: MB, WM

Drafting article: $\mathrm{MB}, \mathrm{RE}, \mathrm{JT}, \mathrm{RC}, \mathrm{MB}$

Critical revision of article: $\mathrm{MB}, \mathrm{RC}, \mathrm{MB}, \mathrm{VS}$

Approval of article: MB, RC, VS

Statistics: MB, WM

Funding secured by: None

\section{References}

[1] Glauber M, Miceli A. State of the art for approaching the mitral valve: sternotomy, minimally invasive or total endoscopic robotic? Eur J Cardiothorac Surg 2015;48:639-41. doi:10.1093/ejcts/ezv312.

[2] Modi P, Hassan A, Chitwood WR. Minimally invasive mitral valve surgery: a systematic review and meta-analysis. Eur J Cardiothorac Surg 2008;34:943-52. doi:10.1016/j.ejcts.2008.07.057.

[3] Cheng DCH, Martin J, Lal A, Diegeler A, Folliguet TA, Nifong LW, et al. Minimally invasive versus conventional open mitral valve surgery: a meta-analysis and systematic review. Innovations (Phila) 2011;6:84-103. doi:10.1097/IMI.0b013e3182167feb. 
[4] Raanani E, Spiegelstein D, Sternik L, Preisman S, Moshkovitz Y, Smolinsky AK, et al. Quality of mitral valve repair: median sternotomy versus port-access approach. J Thorac Cardiovasc Surg 2010;140:86-90. doi:10.1016/j.jtcvs.2009.09.035.

[5] Iribarne A, Russo MJ, Easterwood R, Hong KN, Yang J, Cheema FH, et al. Minimally invasive versus sternotomy approach for mitral valve surgery: a propensity analysis. Ann Thorac Surg 2010;90:1471-7discussion1477-8. doi:10.1016/j.athoracsur.2010.06.034.

[6] Goldstone AB, Atluri P, Szeto WY, Trubelja A, Howard JL, MacArthur JW, et al. Minimally invasive approach provides at least equivalent results for surgical correction of mitral regurgitation: a propensitymatched comparison. J Thorac Cardiovasc Surg 2013;145:748-56. doi:10.1016/j.jtcvs.2012.09.093.

[7] McClure RS, Athanasopoulos LV, McGurk S, Davidson MJ, Couper GS, Cohn LH. One thousand minimally invasive mitral valve operations: early outcomes, late outcomes, and echocardiographic follow-up. J Thorac Cardiovasc Surg 2013;145:1199-206. doi:10.1016/j.jtcvs.2012.12.070.

[8] Murzi M, Cerillo AG, Miceli A, Bevilacqua S, Kallushi E, Farneti P, et al. Antegrade and retrograde arterial perfusion strategy in minimally invasive mitral-valve surgery: a propensity score analysis on 1280 patients. Eur J Cardiothorac Surg 2013;43:e167-72. doi:10.1093/ejcts/ezt043.

[9] Yoo JS, Kim JB, Jung S-H, Choo SJ, Chung CH, Lee JW. Echocardiographic assessment of mitral durability in the late period following mitral valve repair: minithoracotomy versus conventional sternotomy. J Thorac Cardiovasc Surg 2014;147:1547-52. doi:10.1016/j.jtcvs.2013.05.042.

[10] Glauber M, Miceli A, Canarutto D, Lio A, Murzi M, Gilmanov D, et al. Early and long-term outcomes of minimally invasive mitral valve surgery through right minithoracotomy: a 10-year experience in 1604 patients. J Cardiothorac Surg 2015;10:181. doi:10.1186/s13019-015-0390-y.

[11] Atluri P, Stetson RL, Hung G, Gaffey AC, Szeto WY, Acker MA, et al. Minimally invasive mitral valve surgery is associated with equivalent cost and shorter hospital stay when compared with traditional sternotomy. J Thorac Cardiovasc Surg 2016;151:385-8. doi:10.1016/j.jtcvs.2015.08.106.

[12] Lange R, Voss B, Kehl V, Mazzitelli D, Tassani-Prell P, Günther T. Right Minithoracotomy Versus Full Sternotomy for Mitral Valve Repair: A Propensity Matched Comparison. Ann Thorac Surg 2017;103:573-9. doi:10.1016/j.athoracsur.2016.06.055.

[13] Akins CW, Miller DC, Turina MI, Kouchoukos NT, Blackstone EH, Grunkemeier GL, et al. Guidelines for reporting mortality and morbidity after cardiac valve interventions. Ann Thorac Surg 2008;85:1490-5. doi:10.1016/j.athoracsur.2007.12.082.

[14] Tatum JM, Bowdish ME, Mack WJ, Quinn AM, Cohen RG, Hackmann AE, et al. Outcomes after mitral valve repair: A single-center 16-year experience. J Thorac Cardiovasc Surg 2017. doi:10.1016/j.jtcvs.2017.01.047.

[15] Fine JP, Gray RJ. A Proportional Hazards Model for the Subdistribution of a Competing Risk. Journal of the American Statistical Association 2012. doi:10.1080/01621459.1999.10474144;page:string:Article/Chapter.

[16] Gray RJ. A class of K-sample tests for comparing the cumulative incidence of a competing risk. The Annals of Statistics 1988. doi:10.2307/2241622.

[17] Coutinho GF, Antunes MJ. Mitral valve repair for degenerative mitral valve disease: surgical approach, patient selection and long-term outcomes. Heart 2017:heartjnl-2016-311031. doi:10.1136/heartjnl2016-311031.

[18] Nishimura RA, Otto CM, Bonow RO, Carabello BA, Erwin JP, Fleisher LA, et al. 2017 AHA/ACC Focused Update of the 2014 AHA/ACC Guideline for the Management of Patients With Valvular Heart 
Disease: A Report of the American College of Cardiology/American Heart Association Task Force on Clinical Practice Guidelines. Circulation 2017:CIR.0000000000000503. doi:10.1161/CIR.0000000000000503.

[19] David TE, Armstrong S, McCrindle BW, Manlhiot C. Late outcomes of mitral valve repair for mitral regurgitation due to degenerative disease. Circulation 2013;127:1485-92. doi:10.1161/CIRCULATIONAHA.112.000699.

[20] DiBardino DJ, ElBardissi AW, McClure RS, Razo-Vasquez OA, Kelly NE, Cohn LH. Four decades of experience with mitral valve repair: analysis of differential indications, technical evolution, and long-term outcome. J Thorac Cardiovasc Surg 2010;139:76-83-discussion83-4. doi:10.1016/j.jtcvs.2009.08.058.

[21] Suri RM, Clavel M-A, Schaff HV, Michelena HI, Huebner M, Nishimura RA, et al. Effect of Recurrent Mitral Regurgitation Following Degenerative Mitral Valve Repair: Long-Term Analysis of Competing Outcomes. J Am Coll Cardiol 2016;67:488-98. doi:10.1016/j.jacc.2015.10.098.

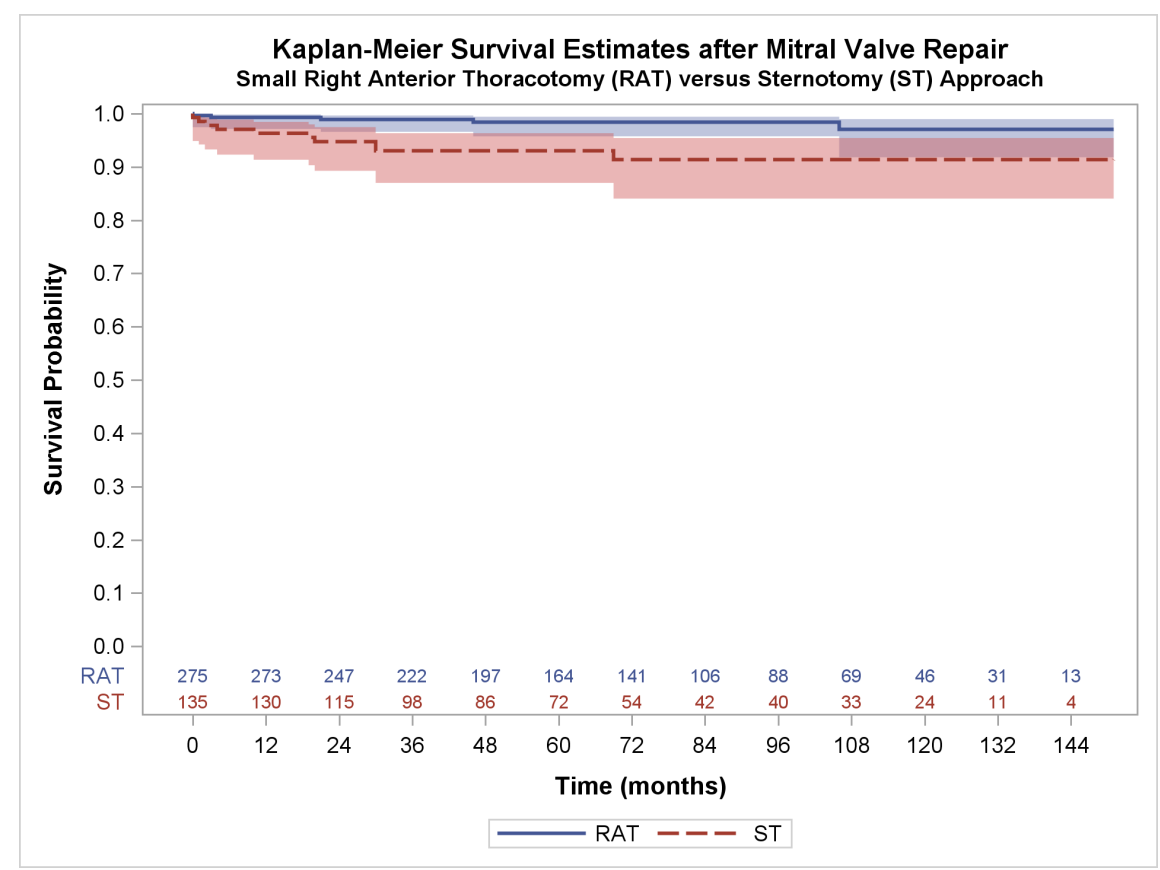




\section{Cumulative Incidence of Progression of MR}

(Mortality as Competing Outcome)

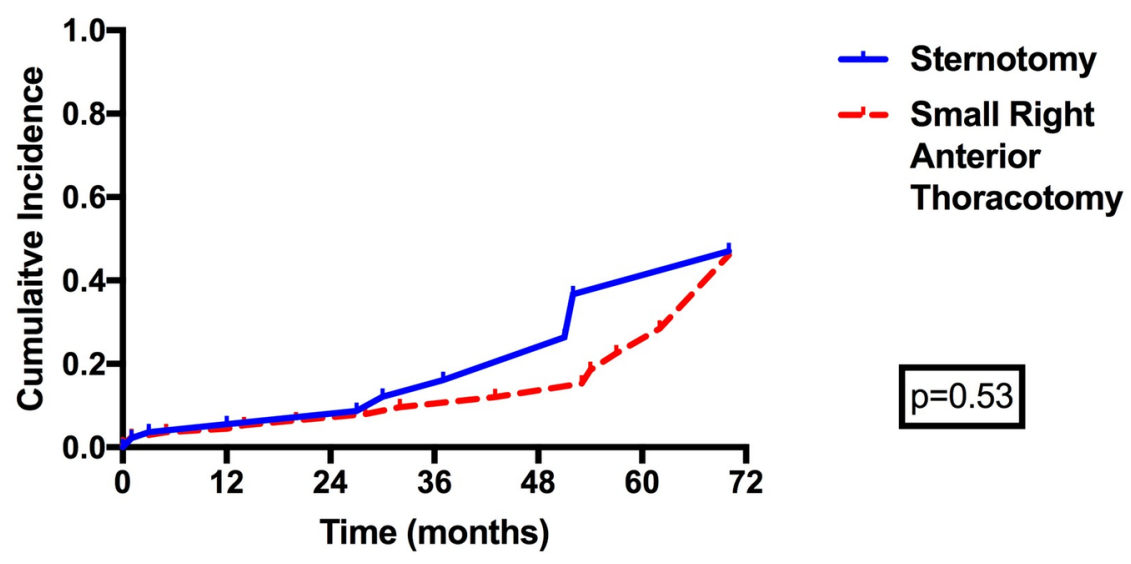

\section{Cumulative Incidence of Mitral Valve Reoperation}

(Mortality as Competing Outcome)

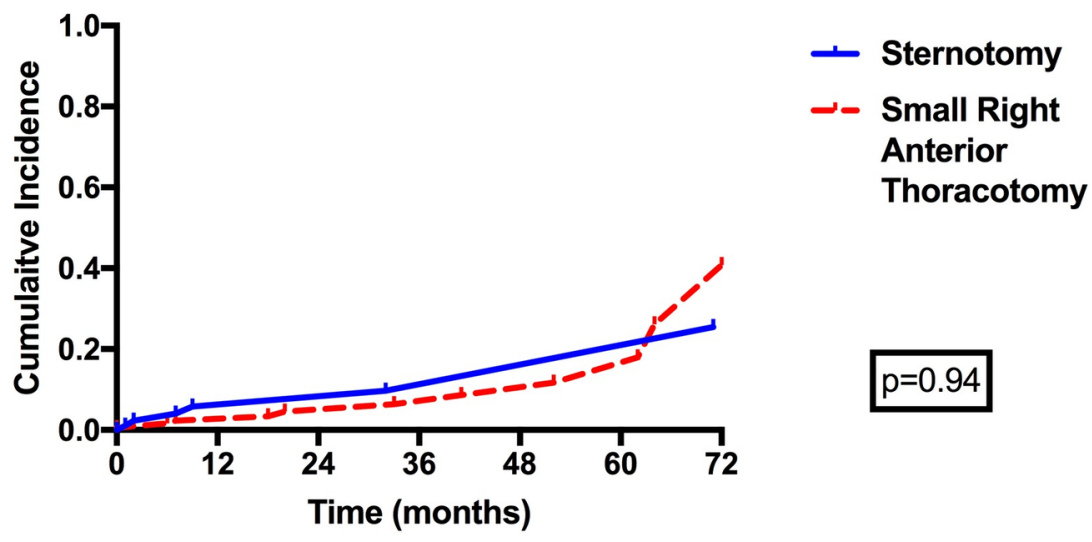




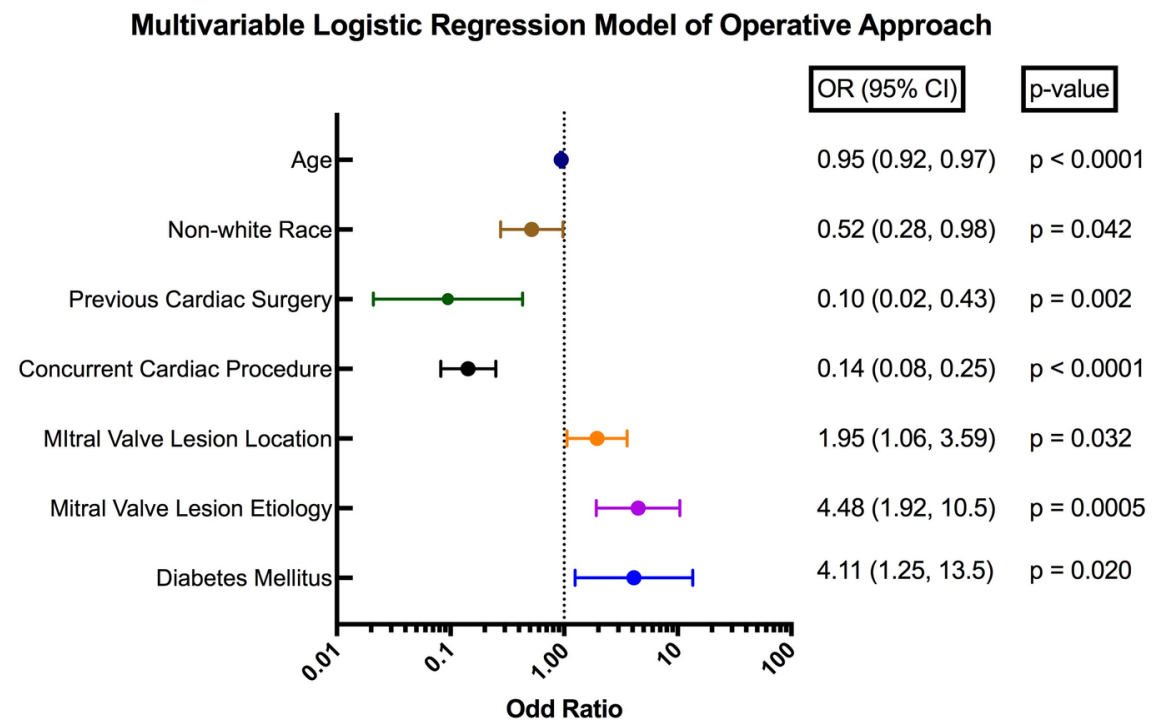

Propensity Adjusted Mutlivariable Analysis of Mortality, Reoperation, and MR progression

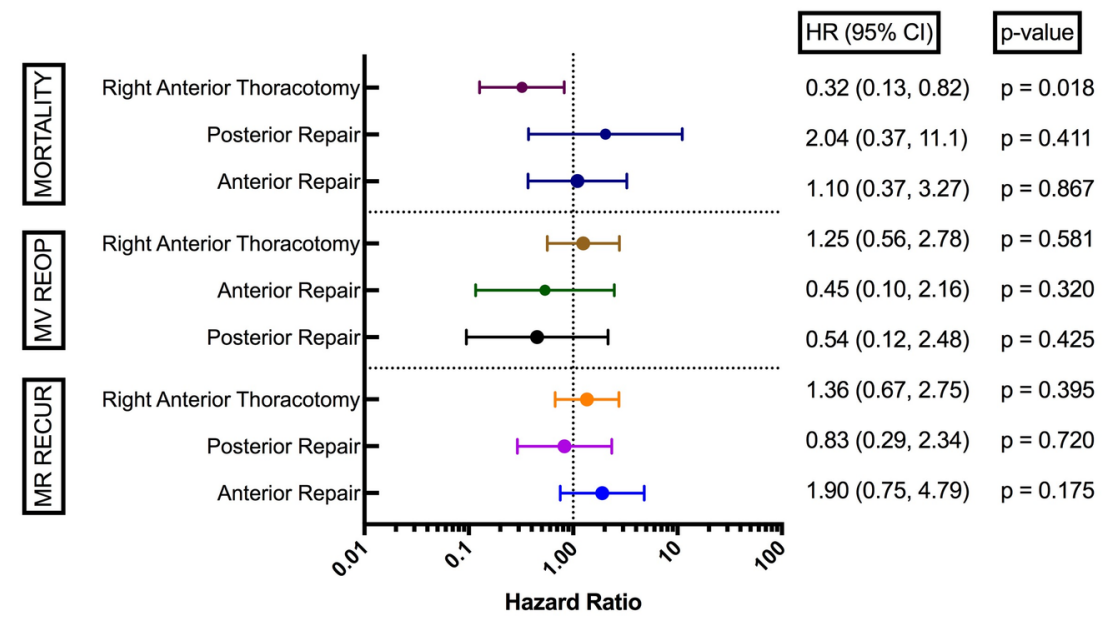

